DOI: $10.4274 /$ tpa.45.366

\title{
Fitalat teması ile plazma amilaz ve lipaz düzeyleri arasındaki ilişkinin pubertal jinekomasti hastalarında değerlendirilmesi
}

\author{
Evaluation of the correlation between plasma amylase and lipase levels \\ and phthalate exposure in pubertal gynecomastia patients
}

\author{
Pınar Erkekoğlu, Belma Giray*, Erdem Durmaz, Elif Özmert**, Murat Kızılgün, Orhan Derman, Kadriye Yurdakök* \\ Hacettepe Üniversitesi Tıp Fakültesi, Ihsan Doğramacı Çocuk Hastanesi, Sosyal Pediatri Anabilim Dalı, Ankara, Türkiye \\ ${ }^{\star}$ Hacettepe Üniversitesi Eczacılık Fakültesi, Farmasötik Toksikoloji Anabilim Dalı, Sı hhiye, Ankara, Türkiye \\ ${ }^{*}$ S. B. Ankara Çocuk Sağlığı ve Hastalığı Hematoloji Onkoloji Eğitim ve Araştırma Hastanesi, Ankara, Türkiye
}

\section{Özet}

Amaç: Bu çalışmanın amacı, endokrin bozucu etkileri bilinen di(2-etilhekzil)fitalat (DEHP) ve metaboliti mono (2-etilhekzil) fitalat (MEHP) plazma düzeylerinin yüksek olduğu belirlenen pubertal jinekomasti hastalarında plazma fitalat düzeyleri ile pankreatik lipaz ve $\alpha-a m i l a z$ düzeyleri arasındaki ilişkinin incelenmesi ve fitalatların pankreas üzerindeki olası etkilerinin değerlendirilmesidir.

Gereç ve Yöntem: Çalışma grubu 40 pubertal jinekomasti hastasından oluşmaktadır. Plazma fitalat düzeyleri DEHP ve MEHP mono (2-etikhekzil) Yüksek basınçlı sıvı kromatografisi (high pressure liquid chromatography) kullanılarak belirlenmiştir. Lipaz ve $\alpha$-amilaz düzeyleri enzimatik kolorimetrik yöntemle ölçülmüştür. İncelenen değişkenler arasındaki ilişki, ilişki katsayısı saptanarak incelenmiştir.

Bulgular: Jinekomasti hastalarındaki plazma DEHP ve MEHP düzeyleri, kontrol grubuna oranla önemli düzeyde yüksek bulunmuştur. Alfa-amilaz ve MEHP düzeyleri arasında jinekomasti hastalarında $(r=-0,388, p<0,05)$ ve tüm çalışma grubunda $(r=-0,353, p<0,05)$ negatif ilişki saptanmıştır. DEHP ve $\alpha$-amilaz düzeyleri arasında da tüm çalışma grubunda önemli düzeyde negatif ilişki $(r=-0,323, p<0,05)$ saptanmıştır.

Çıkarımlar: Sonuçlar fitalat varlığının $\alpha$-amilaz salgılanmasında belirgin azalmalara neden olabileceğine işaret etmektedir. Gözlenen bu ters ilişki fitalatların PPAR y (peroxisome proliferator-activated receptor gamma) etkinliği ile açıklanabilir. (Türk Ped Arş 2010; 45: 366-70)

Anahtar sözcükler: $\alpha$-amilaz, di (2-etilhekzil) fitalat, jinekomasti, lipaz, mono (2-etilhekzil) fitalat

\section{Summary}

Aim: The aim of this study was to determine the correlation between plasma phthalate and pancreatic lipase and $\alpha$-amylase levels in pubertal gynecomastia patients with high plasma levels of di(2-ethylhexyl)phthalate (DEHP) and its metabolite mono (2-ethylhexyl) phthalate (MEHP) which are known endocrine disrupting chemicals and to evaluate the possible effects of phthtalates in pancreas.

Material and Method: The study group was composed of 40 pubertal gynecomastia patients. Plasma phthalate levels (Di(2-ethylhexyl)phthalate, DEHP and mono (2-ethylhexyl) phthalate, MEHP) were determined using HPLC. Plasma lipase and $\alpha$-amylase levels were measured by using enzymatic colorimetric assay.

Results: Plasma DEHP and MEHP levels in gynecomatia patients were higher than the control group significantly. Significant negative correlations existed between $\alpha$-amylase and MEHP levels in gynecomastia $(r=-0.388, p<0.05)$ and overall study groups $(r=-0.353, p<0.05)$. Negative correlation between DEHP and $\alpha$-amylase levels was found to be significant in overall study group $(r=-0.323, p<0.05)$.

Conclusions: The results suggest that phthalate exposure might cause significant decreases in $\alpha$-amylase secretion. The inverse correlation observed might be explained by the PPAR (peroxisome proliferator-activated receptor gamma)-activation of phthalates. (Turk Arch Ped 2010; 45: 366-70)

Key words: $\alpha$-amylase, Di (2-ethylhexyl) phthalate (DEHP), gynecomastia, lipase, mono (2-ethylhexyl) phthalate (MEHP)

Yazışma Adresi/Address for Correspondence: Dr. Belma Giray, Hacettepe Üniversitesi Eczacllık Fakültesi Farmasötik Toksikoloji Anabilim Dall, Sıhhiye, Ankara, Türkiye E-posta: bgiray@hacettepe.edu.tr Geliş Tarihi/Received: 22.02.2010 Tarihi/Accepted: 09.08.2010 Türk Pediatri Arşivi Dergisi, Galenos Yayınevi tarafindan basılmıștr. / Turkish Archives of Pediatrics, published by Galenos Publishing 


\section{Giriş}

Endokrin işlevleri farklı mekanizmalarla etkileyerek değişikliklere neden olan "endokrin bozucu kimyasal maddeler" son yıllarda pek çok araştırmanın konusu olmuştur. Bu bileşikler, endojen hormonlar üzerinde agonistik veya antagonistik etki gösterebilecekleri gibi, hücre sinyal iletim yolaklarını etkileyebilir veya almaç (reseptör) "ekspresyonlarını" değiștirebilirler. Pubertenin herhangi bir neden bulunmaksızın erken görülmesi, endokrin bozucuların bu süreç üzerindeki olası etkilerini düşündürmektedir (1). Fitalatlar, yapı gereçleri, besin ambalaj gereci, tekstil, oyuncak, çocuk bakım ürünleri (biberon ve emzikler dahil), kan torbası, IV sIVı torbası, enfüzyon seti ve tıbbi malzeme dahil, poli vinil klorür (PVC) tipi plastik ürünlerin esnekliğini ve dayanıklıı̆ını sağlamak üzere plastikleştirici olarak kullanılan ve bu nedenle çok yaygın olarak karşılaşılan kimyasal maddelerdir. Kozmetikler, parfümler ve sabunlar dahil kişisel bakım ürünlerinde de yaygın olarak kullanılırlar ve çok büyük hacimlerde üretilip tüketilirler. Plastik matriksinden sızmaları nedeniyle tıbbi uygulamalarla temas edildiği gibi, toplumun fitalatlara teması genellikle diyet yoluyla ve kozmetik bakım ürünleri yoluyla olmaktadır. Di (2-etilhekzil) fitalat (DEHP), en yaygın kullanılan fitalat türevidir ve örneğin PVC-tıbbi malzemelerde \%20-40 oranında DEHP bulunmaktadır (1-4). Di (2-etilhekzil) dahil fitalatlar, endokrin bozucu kimyasal maddeler olarak değerlendirilmektedir. Özellikle çocukların bu etkiye daha duyarlı olduğu bilinmektedir (1). Fitalatlar hayvan karsinojenleridir ve fötal ölüm, malformasyonlar, anti-androjenik etki, teratojenite ve özellikle laboratuvar hayvanlarında testiküler hasar ile üreme sistemi üzerinde diğer toksik etkilere neden olabilirler $(3,4)$. Fitalatlarla doğum öncesi dönemde karşılaşmanın erkek sıçanların üreme sisteminin gelişimini olumsuz etkilediği bildirilmiştir (5). Di (2-etilhekzil) fitalat, insanlar tarafından üretilen ve maruz kalınan en yaygın fitalatlardan biridir ve plastiklere esneklik katmak için kullanıı ır (3). Di (2-etilhekzil) fitalat, bir östrojen agonisti ve testosteron antagonisti olarak kabul edilmektedir; ancak toksisite mekanizmaları tam aydınlatılamamıştır (5). Mono (2-etilhekzil) fitalat (MEHP) DEHP'in ana metabolitidir ve DEHP'den daha toksiktir (4).

Jinekomasti meme dokusunun glandüler artışıdır. Jinekomastinin birçok nedeni bulunmaktadır, ancak kesin patojenezi bilinmemektedir $(6,7)$. Pubertal jinekomastinin gelişimi altında yatan temel nedenlerin meme dokusunda östrojen uyarısı ve androjen engellenmesi arasındaki dengesizlik olduğu bildirilmektedir. Bu dengesizliğin sebebi, östrojen etkinliğinin fazlalığı, androjen etkinlik eksikliği veya bu etkilerin birlikteliğidir (6). Endokrin bozucular da pubertal jinekomastinin bir nedeni olarak görülmektedir. Lavanta (Lavandula augustifolia) yağı ve çay ağacı yağı (Melaleuca alternifolia) içeren bir balsam, lavanta kokulu sabun, deri losyonu, şampuanı ve saç şekillendirici içeren ürünler kullanan üç sağlıklı prepubertal çocukta jinekomasti geliştiği bildirilmiş, bu bakım ürünlerinin kullanımının kesilmesiyle çocuklar normale dönmüştür. Lavanta ve çay ağacı yağlarının anti-androjenik etkileri insan meme kanseri hücre kültürleri ile de gösterilmiştir (8).

Peroksizomlar hidrojen peroksit $\left(\mathrm{H}_{2} \mathrm{O}_{2}\right)$ içeren ve lipit metabolizması için çok önemli olan organellerdir. Peroksizom artışı peroksizomların sayısı, hacmi ve yağ asidi oksidasyonundaki artışla belirgin bir durumdur. Fitalatların peroksizom çoğalması üzerine etkileri de uzun süredir bilinmektedir ve kanser yapıcı etkilerinin altında bu mekanizmanın yattı̆̆ı bildirilmiştir (9). Kemiricilerde yapılan çalışmalarda, fitalat esterlerinin ve benzer etki gösteren hipolipidemik ilaçların karaciğer parankimal hücrelerinde peroksizomal yağ asidi $\beta$-oksidasyonunu sağlayan enzimlerin ve dolayısıyla $\mathrm{H}_{2} \mathrm{O}_{2}$ miktarını artırdıkları ve buna bağlı tümör gelişimine neden oldukları gösterilmiştir (9). Sıçanlarda pankreatik asiner-hücre tümörlerinin (PACT'lar) altında yatan başlatıcı temel mekanizmanın da peroksizom artıııı aktive reseptör- $\alpha$ (PPAR $\alpha$ )'nın karaciğerde aktivasyonu olabileceği ve takiben safra sentezi ve bileşimindeki değişimle ilerlediği bildirilmiştir (9).

Diğer taraftan, epidemiyolojik çalışmalar fitalatlar, dioksinler ve kalıcı organik kirleticilerin insanlarda kan glukoz dengesini bozduğunu göstermiştir ve kan glukozu değişimlerinin pankreasta enflamasyonun iyi bir göstergesi olabileceği bilinmektedir (10).

Pankreatit gibi pankreas hastalıkları klinikte lipaz ve $\alpha$-amilaz düzeyleri ile değerlendirilmektedir. Bu enzimler pankreasta enflamasyonun iyi birer göstergesi kabul edilmektedirler (11). Pankreatik $\alpha$-amilaz uzun zincirli karbonhidratları glukoz ve maltoz gibi küçük şekerlere yıkar (12). Pankreatik lipaz ise pankreas tarafından salgılanan ve yağ moleküllerini hidroliz ile yıkan bir enzimdir. Lipazlar aynı zamanda DEHP'in metabolizmasında görev alan ve DEHP'i MEHP'e yıkan esterazlardır (13).

$\mathrm{Bu}$ çalsşma, endokrin bozucu etkileri bilinen DEHP ve metaboliti MEHP'in bir endokrin organ olarak pankreasta olası etkilerini değerlendirebilmek üzere tasarlanmış; bu amaçla plazma DEHP ve MEHP düzeylerinin yüksek olduğu belirlenen jinekomasti hastası puberte dönemindeki çocuklarda plazma DEHP ve MEHP düzeylerinin pankreatik amilaz ve lipaz düzeyleri ile ilişkisi kontrol grubu ile karşılaştırmalı olarak incelenmiştir.

\section{Gereç ve Yöntem}

\section{Çalışma grubu}

Hacettepe Universitesi İhsan Doğramacı Çocuk Hastanesi Adölesan Birimi'nde pubertal jinekomasti tanısı alan, 11-15 yaş arası (ortalama yaş 13,2 $\pm 0,9$ ) 40 erkek cocuk çalışma grubunu oluşturmuştur. Bu hastaların 34'ünde çift taraflı jinekomasti, altısında ise tek taraflı jinekomasti tanısı konmuştur. Kontrol grubu ise yaş ve 
cinsiyet yönünden eşleştirilen (ortalama yaş 13,2 $\pm 1,1$ ), jinekomasti ve başka bir endokrinolojik veya kronik hastalığı bulunmayan, birden başlayan yakınmalar ile Adölesan Birimi'ne başvuran 21 çocuktan oluşmuştur. Olgu alımı Ekim-Aralık 2007 tarihleri arasında yapılmıştır. Çalışma, "Helsinki Deklerasyonu"na göre Hacettepe Üniversitesi Etik Kurulu'nca onaylanmıştır. Tüm çocukların gönüllü olarak kan verdiklerini belirten imzalı aydınlatılış onam formları kan örnekleri toplanmadan önce aileleri ile görüşülerek alınmıştır.

Deney boyunca kullanılan cam malzeme $400^{\circ} \mathrm{C}$ 'de dört saat bekletilerek plastizerlerden arındırılmıştır. Çalışma gruplarında yer alan çocukların brakiyal venlerinden, arka ucunda plastik yapısı bulunmayan steril iğne ucu ile damlama seklinde $10 \mathrm{ml}$ kan örneği özel hazırlanmış heparinli cam tüplere alınmıştır. Kanlar 800xg'de 15 dakika santrifüjlenmiş, plazma ayrılmış ve çalışılana kadar $-80^{\circ} \mathrm{C}^{\prime}$ de saklanmıştır.

Plazma DEHP ve MEHP düzeyleri, Paris ve ark.'ları (15) tarafından geliştirilen ve tarafımızdan değiştirilen bir yöntem ile (14) HPLC'de tayin edilmiştir. Plazma lipaz ve $\alpha$-amilaz düzeyleri kolorimetrik kitler kullanılarak (Roche Diagnostic $\mathrm{GmbH}^{\circledR}$, Mannheim, Germany) MODULAR-P 800 (Roche-Hitachi ${ }^{\circledR}$ ) ölçülmüştür.

\section{İstatistiksel değerlendirme}

Tüm sonuçlar ortalama standart hata olarak verilmiştir. Gruplar arası farkın önem kontrolleri, KruskalWallis testini takiben Bonferroni düzeltmeli Mann-Whitney U testi kullanılarak yapılmıştır. Değişkenler arasındaki ilişki, "Pearson" korelasyon yöntemi ile incelenmiştir. Tüm istatistik değerlendirmelerinde "Statistical Package for Social Sciences (SPSS), versiyon 17.0 kullanılmıştır.

\section{Bulgular}

Pubertal jinekomasti hastalarında plazma DEHP

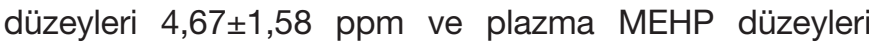
$3,19 \pm 1,41$ ppm olarak tayin edilmiş ve bu değerlerin

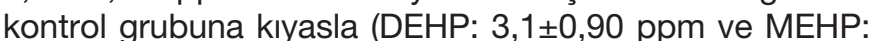
$1,39 \pm 0,36$ ppm) önemli ölçüde $(p<0,05)$ yüksek olduğu bulunmuştur (14). Çalışma gruplarında ölçüden $\alpha$-amilaz ve lipaz değerleri Tablo 1'de verilmiştir. Jinekomasti grubunda $\alpha$-amilaz düzeylerinde bir azalma eğilimi (\%15) gözlenmekle birlikte, bu farkın istatistiksel açıdan önemli olmadığı belirlenmiştir ( $p>0,05)$. İstatistiksel testin gücü $\alpha$-amilaz için \%66,7, lipaz için \%40 olarak belirlenmiştir ve bu çalışmanın zayıf yanı olarak görülmektedir. Tek taraflı ve çift tarafı jinekomasti hastalarında saptanan $\alpha$-amilaz değerleri gerek birbirleriyle gerekse kontrol grubuyla karşılaştırılmış, gruplar arası fark önemli bulunmamıştır $(p>0,05)$. Pankreatik lipaz düzeylerinin de gerek tek taraflı gerekse çift taraflı pubertal jinekomasti hastalarında kontrol grubuna kıyasla farklı olmadığı $(p>0,05)$ belirlenmiştir.

Pubertal jinekomasti ve kontrol grupları ile her iki grubu kapsayan tüm çalışma grubunda plazma DEHP, plazma MEHP ve pankreatik $\alpha$-amilaz ve lipaz düzeyleri arasındaki ilişkiye ait Pearson korelasyon katsayıları Tablo 2'de verilmiştir. Mono (2-etilhekzil) fitalat ve $\alpha$-amilaz düzeyleri arasında gerek pubertal jinekomasti grubunda $(r=-0,388$, $p<0,05)$, gerekse tüm çalışma grubunda $(r=-0,353$, $p<0,05)$ istatistiksel olarak önemli ölçüde negatif ilişki olduğu bulunmuştur. Ayrıca, tüm çalışma grubunda DEHP ve $\alpha$-amilaz düzeyleri arasında yine belirgin bir negatif ilişki gözlenmiştir ( $r=-0,323, p<0,05)$.

Tablo 1. Çalışma gruplarında DEHP, MEHP, $\alpha$-amilaz ve lipaz düzeyleri

\begin{tabular}{|c|c|c|c|c|}
\hline Grup & DEHP (ppm) & MEHP (ppm) & $\alpha$-Amilaz (U/L) & Lipaz (U/L) \\
\hline Kontrol Grubu (n=20) & $3,10 \pm 0,90^{\mathrm{a}}$ & $1,39 \pm 0,36^{a}$ & $62,55 \pm 3,98^{a}$ & $18,37 \pm 1,30^{\mathrm{a}}$ \\
\hline $\begin{array}{l}\text { Jinekomasti Grubu } \\
(n=40)\end{array}$ & $\begin{array}{c}4,67 \pm 1,58^{b} \\
(p<0,001 \text { vs kontrol) }\end{array}$ & $\begin{array}{c}3,19 \pm 1,41^{\mathrm{b}} \\
(\mathrm{p}<0,001 \text { vs kontrol) }\end{array}$ & $\begin{array}{c}53,89 \pm 3,37^{a} \\
(p=0,302 \text { vs kontrol) }\end{array}$ & $\begin{array}{c}19,58 \pm 0,96^{a} \\
(p=0,755 \text { vs kotrol) }\end{array}$ \\
\hline $\begin{array}{l}\text { Tek taraflı jinekomasti } \\
(n=6)\end{array}$ & $\begin{array}{c}4,03 \pm 0,43^{b} \\
(p<0,001 \text { vs kontrol) }\end{array}$ & $\begin{array}{c}2,60 \pm 0,25^{\mathrm{b}} \\
\text { ( } p<0,001 \text { vs kontrol) }\end{array}$ & $\begin{array}{c}56,00 \pm 7,52^{a} \\
(p=0,656 \text { vs kontrol) } \\
(p=0,592 \text { vs çift taraflı } \\
\text { jinekomasti grubu) }\end{array}$ & $\begin{array}{c}21,01 \pm 2,32^{a} \\
(p=0,249 \text { vs kontrol) } \\
(p=0,575 \text { vs çift taraflı } \\
\text { jinekomasti grubu) }\end{array}$ \\
\hline $\begin{array}{l}\text { Çift tarafı jinekomasti } \\
(n=34)\end{array}$ & $\begin{array}{c}4,86 \pm 0,27^{b} \\
(p<0,001 \text { vs kontrol) }\end{array}$ & $\begin{array}{c}3,27 \pm 0,13^{b} \\
(p<0,001 \text { vs kontrol) }\end{array}$ & $\begin{array}{c}53,48 \pm 3,48^{a} \\
(p=0,082 \text { vs kontrol) } \\
(p=0,592 \text { vs tek taraflı } \\
\text { jinekomasti grubu) }\end{array}$ & $\begin{array}{c}19,26 \pm 1,05^{a} \\
\text { ( } p=0,425 \text { vs kontrol) } \\
\text { ( } p=0.575 \text { vs çift taraflı } \\
\text { jinekomasti grubu) }\end{array}$ \\
\hline
\end{tabular}

a,b Farklı harflerle gösterilen üst simgeler iki ortalamanın birbirinden farklı olduğunu belirtmektedir. P değerleri her bir ortalamanın altında belirtilmiştir

Tablo 2. $\alpha$-Amilaz ve lipaz düzeyleri ile fitalat düzeyleri arası ilişki (pearson korelasyon katsaylları)

\begin{tabular}{|l|c|c|c|c|}
\hline Group & $\alpha$-Amilaz-DEHP & Lipaz- DEHP & $\alpha$-Amilaz-MEHP & Lipaz- MEHP \\
\hline Kontrol Grubu $(n=20)$ & $-0,412$ & 0,166 & $-0,277$ & $-0,080$ \\
\hline Jinekomasti Grubu $(n=40)$ & $-0,270$ & 0,106 & $-0,388^{*}$ & $-0,055$ \\
\hline Tüm Çalışma Grubu $(n=60)$ & $-0,323^{*}$ & 0,152 & $-0,353^{*}$ & $-0,076$ \\
\hline
\end{tabular}




\section{Tartışma}

Di (2-etilhekzil) dahil fitalatlar, endokrin bozucu kimyasal maddeler olarak değerlendirilmektedir. Pubertal jinekomasti gibi endokrin temeli olan patolojik durumlarda özellikle endokrin bozucu çevresel kimyasal maddelerin rolünün olup olmadığı konusu ilgi çekmekte ve incelenmektedir. Pubertal jinekomasti tanısı almış çocuklarda tarafımızdan yapılan çalışmada gerek DEHP gerekse ana metaboliti MEHP düzeylerinin kontrol grubuna oranla istatistiksel olarak anlamlı ölçüde yüksek olduğu belirlenmiş ve pubertal jinekomastinin patojenezinde fitalatların rolü olabileceği konusunda önemli bir bulgu sağlanmıştır (14).

Endokrin bozucu özellikleri olduğu bildirilen birçok çevresel kimyasal maddenin pankreasta da önemli ölçüde hasara neden olabileği ileri sürülmektedir. Poliester, PVC polimerizasyonu, plastiklerin antioksidasyonu için kullanılan, $17 \beta$-estradiol benzeri etki gösteren bir ksenoöstrojen olan bisfenol A'nın (BPA) çevrede bulunan miktarlarının farelerin pankreasında ciddi bozukluklara neden olabileceği gösterilmiștir (10). Ayrıca BPA'nın taze hazırlanan Langerhans adacığı kültürlerinde insülin salımından sorumlu, $\beta$-hücrelerini ve glukagon salımından sorumlu $\alpha$-hücrelerini hızlı ve genomik olmayan bir mekanizmayla etkilediği belirlenmiştir ve bu etkileri nedeniyle glukoz metabolizmasını bozduğu bildirilmiştir (10). Bu nedenle benzer etkili endokrin bozucuların da glukoz metabolizmasını etkileyebilecekleri belirtilmektedir (10).

Bir başka çalışmada, \%2 DEHP içeren diyetle beslenen farelerin pankreas ağırlığında önemli ölçüde azalma gözlendiği bildirilmiştir (16). Ayrıca, DEHP'in pankreatik enzim düzeylerini etkileyebileceği belirtilmiştir. Bu konuda yapılmış bir diğer çalışmada DEHP'in plazma trigliserit düzeylerini ve karaciğer dışı lipoprotein lipaz aktivitesini artırdığı bildirilmiştir (17). Di (2-etilhekzil) fitalatın fare pankreasında lipit peroksidasyonu uyardığını bildiren bir çalışma da bulunmaktadır (18).

Plazma DEHP ve MEHP düzeyleri anlamlı ölçüde yüksek bulunan pubertal jinekomasti hastalarında pankreatik enzim düzeylerinin incelendiği bu çalışmada, kontrol grubu ve jinekomasti hastaları arasında incelenen değişkenlerde istatistiksel açıdan önemli bir fark bulunamamıştır. Jinekomasti tanısı konulan çocuklarda $\alpha$-amilaz düzeylerinde bir azalma eğilimi ( $\% 15)$ gözlenmekle birlikte, bu fark istatistiksel olarak anlamlı değildir. Diğer taraftan, incelenen değişkenler arasındaki ilişki değerlendirildiğinde $\alpha$-amilaz düzeyleri ile MEHP düzeyleri arasında gerek jinekomasti grubunda $(r=-0,388)$ gerekse tüm çalışma grubunda $(r=-0,353)$ istatistiksel açıdan anlamlı $(p<0,05)$ negatif bir ilişki olduğu belirlenmiştir. Di (2-etilhekzil) fitalat ve $\alpha$-amilaz düzeyleri arasında ise jinekomasti ve kontrol grubunda istatistiksel olarak önemli olmayan yüksek bir negatif ilişki saptanmış (sırasıyla $r=-0,027$ ve $r=-0,041$ ); tüm çalışma grubunda ise anlamlı ölçüde negatif yönde \%32'lik bir ilişkinin olduğu tespit edilmiştir. Bu veriler, sadece fitalat temasıyla ortaya çıkabilecek pubertal jinekomasti gibi patolojik durumlarda değil, yüksek oranda fitalata maruz kalan tüm bireylerde pankreatik değişikliklerin gözlenebileceğine işaret etmektedir. Diğer taraftan, lipaz düzeyleri ile ise fitalat düzeyleri arasında herhangi bir ilişki bulunamamıştır.

Mono (2-etilhekzil) fitalatın meme dokusunda PPAR $\alpha$ ve PPAR $\gamma$ aktivasyonu yaptığı bildirilmiştir. PPAR $\gamma$ 'nin ise, adiposit dokunun farklılaşması ve glükoz dengesinin sağlanmasında çok önemli bir rolü olduğu bilinmektedir. Son yapılan çalışmalarda antidiyabetik olarak kullanılan rosiglitazon gibi PPAR $\gamma$ ligandlarının sodyum taurokolat verilen erkek Wistar sıçanlarda serum amilaz düzeylerini düşürdüğü belirlenmiştir (19). Bunun nedeninin yüksek doz PPAR $\gamma$ ligandı varlığına sonucu pankreas ağırlığının azalması olabileceği belirtilmiştir (19). Tarafımızdan yapılan bu çalışmada MEHP ve $\alpha$-amilaz düzeyleri arasında görülen negatif ilişki fitalatların PPAR üzerindeki etkilerine ve fitalat teması ile pankreas ağırlığında azalma gözlenmesine bağlanabilir. Diğer taraftan, söz konusu ilişkilerin özellikle tüm çalışma grubunda anlamlı ölçüde gözlenmesi, fitalat temasının jinekomasti oluşumuna bağlı olmaksızın $\alpha$-amilaz düzeylerinde azalmalara neden olabileceği bulgusunu destekler niteliktedir. Bununla birlikte, çalışma grubunda $\alpha$-amilaz ve lipaz düzeylerinde kontrol grubuna oranla anlamlı bir değişiklik gözlenmemesi ve belirlenen ilişkileri etkileyebilecek başka etmenlerin de bulunabileceği dikkate alındığında tam bir neden-sonuç ilişkisinin ortaya konmasının güç olduğu anlaşılmaktadır. Fitalatların ve benzer etki gösteren diğer endokrin bozucuların pankreas ve endokrin sistemler üzerindeki etkilerini inceleyen ve bu etkilerin mekanizmalarını aydınlatan daha çok sayıda ve kapsamlı çalışmaya intiyaç bulunmaktadır.

\section{Kaynaklar}

1. Nebesio TD, Pescovitz OH. Part VII: Environmental effects on puberty. The role of endocrine disruptors in pubertal development. In: Walvoord EC, Pescovitz OH, (eds). When Puberty is Precocious: Scientific and Clinical Aspects. New Jersey: Humana Press; 2007; 425-42.

2. Frederiksen H, Skakkebaek NE, Andersson AM. Metabolism of phthalates in humans. Mol Nutr Food Res 2007; 51: 899-911.

3. ATDSR. Toxicological Profile for Diethylphthalate. Department of Health and Human Services, Public Health Service, Agency for Toxic Substances and Disease Registry, Atlanta; USA, 1995.

4. Kai $H$, Shono T, Tajiri $T$, Suita S. Long-term effects of intrauterine exposure to mono-n-butyl phthalate on the reproductive function of postnatal rats. J Pediatr Surg 2005; 40: 429-33.

5. National Toxicology Program Center for the Evaluation of Risks to Human Reproduction NTP-CERHR Expert Panel Report NPT-CERHR-DEHP-00 (National Toxicology Program Center for the Evaluation of Risks to Human Reproduction, Washington DC; USA, 2000. 
6. Narula HS, Carlson HE. Gynecomastia. Endocrinol Metab Clin North Am 2007; 36: 497-519.

7. Ma NS, Geffner Mitchell E. Gynecomastia in prepubertal and pubertal men. Curr Opin Pediatr 2008; 20: 465-70.

8. Henley DV, Lipson N, Korach KS, Bloch CA. Pubertal gynecomastia linked to lavender and tea tree oils. $\mathrm{N}$ Engl $\mathrm{J}$ Med 2007; 356: 479-85.

9. Klaunig JE, Babich MA, Baetcke KP, et al. PPARalpha agonist-induced rodent tumors: modes of action and human relevance. Crit Rev Toxicol 2003; 33: 655-780.

10. Ropero AB, Alonso-Magdalena P, García-García E, Ripoll C Fuentes E, Nadal A. Bisphenol-A disruption of the endocrine pancreas and blood glucose homeostasis. Int $\mathrm{J}$ Androl 2008; 31: 194-200.

11. Lott JA. Inflammatory diseases of the pancreas. Crit Rev Clin Lab Sci 1982; 17: 201-28.

12. Pieper-Bigelow $C$, Strocchi A, Levitt MD. Where does serum amylase come from and where does it go? Gastroenterol Clin North Am 1990; 19: 793-810.

13. Eckfeldt JH, Levitt MD. Diagnostic enzymes for pancreatic disease. Clin Lab Med 1989; 9: 731-43.
14. Durmaz E, Ozmert EN, Erkekoglu P, et al. Plasma phthalate levels in pubertal gynecomastia. Pediatrics 2010; 125: 122-9.

15. Paris I, Ruggieri F, Mazzeo P, Carlucci G. Simultaneous determination of di(2-ethylhexyl) phthalate and mono(2-ethylhexyl) phthalate in human plasma by HPLC. Anal Lett 2003; 36: 2645-54.

16. Miura $Y$, Naito M, Ablake M, et al. Short-term effects of di-(2ethylhexyl) phthalate on testes, liver, kidneys and pancreas in mice. Asian J Androl 2007; 9: 199-205.

17. Mocchiutti NO, Bernal CA. Effects of chronic di(2-ethylhexyl) phthalate intake on the secretion and removal rate of triglyceride-rich lipoproteins in rats. Food Chem Toxicol 1997; 35: 1017-21.

18. Venkata NG, Robinson JA, Cabot PJ, Davis B, Monteith GR, Roberts-Thomson SJ. Mono (2-ethylhexyl) phthalate and mono-n-butyl phthalate activation of peroxisome proliferator activated-receptors alpha and gamma in breast. Toxicol Lett 2006; 163: 224-34.

19. Chen C, Xu S, Wang WX, et al. Rosiglitazone attenuates the severity of sodium taurocholate-induced acute pancreatitis and pancreatitis-associated lung injury. Arch Med Res 2009; 40: $79-88$. 